\title{
Research on the Corrosion Fatigue Property of 2524-T3 Aluminum Alloy
}

\author{
Chi Liu ${ }^{1}$, Liyong Ma ${ }^{2,3}, *\left(\mathbb{D}\right.$, Ziyong Zhang $^{3}$, Zhuo Fu $^{1}$ and Lijuan Liu ${ }^{2}$ \\ 1 School of Mechanical and Electrical Engineering, Changsha University, Changsha 410022, China; \\ liuchi@ccsu.edu.cn (C.L.); z20141061@ccsu.edu.cn (Z.F.) \\ 2 School of Mechanical Engineering, Hebei University of Architecture, Zhangjiakou 075031, China; \\ zyq1292@hebiace.edu.cn \\ 3 School of Mechanical Engineering and Automation, Beihang University, Beijing 100091, China; \\ ZY1907321@buaa.edu.cn \\ * Correspondence: maliyong@buaa.edu.cn; Tel.: +86-180-7516-1888
}

Citation: Liu, C.; Ma, L.; Zhang, Z.; $\mathrm{Fu}, \mathrm{Z}$;; Liu, L. Research on the Corrosion Fatigue Property of 2524-T3 Aluminum Alloy. Metals 2021, 11, 1754. https://doi.org/ $10.3390 /$ met11111754

Academic Editor: Dariusz Rozumek

Received: 28 September 2021

Accepted: 29 October 2021

Published: 1 November 2021

Publisher's Note: MDPI stays neutral with regard to jurisdictional claims in published maps and institutional affiliations.

Copyright: (c) 2021 by the authors. Licensee MDPI, Basel, Switzerland. This article is an open access article distributed under the terms and conditions of the Creative Commons Attribution (CC BY) license (https:// creativecommons.org/licenses/by/ $4.0 /)$.

\begin{abstract}
The 2524-T3 aluminum alloy was subjected to fatigue tests under the conditions of $R=0$, $3.5 \% \mathrm{NaCl}$ corrosion solution, and the loading cycles of $10^{6}$, and the S-N curve was obtained. The horizontal fatigue limit was $169 \mathrm{MPa}$, which is slightly higher than the longitudinal fatigue limit of $163 \mathrm{MPa}$. In addition, detailed microstructural analysis of the micro-morphological fatigue failure features was carried out. The influence mechanism of corrosion on the fatigue crack propagation of 2524-T3 aluminum alloy was discussed. The fatigue source characterized by cleavage and fracture mainly comes from corrosion pits, whose expansion direction is perpendicular to the principal stress direction. The stable propagation zone is characterized by strip fractures. The main feature of the fracture in the fracture zone is equiaxed dimples. The larger dimples are mixed with second-phase particles ranging in size from 1 to $5 \mu \mathrm{m}$. There is almost a one-to-one correspondence between the dimples and the second-phase particles. The fracture mechanism of 2524 alloy at this stage is transformed into a micro-holes connection mechanism, and the nucleation of micropores is mainly derived from the second-phase particles.
\end{abstract}

Keywords: 2524-T3 aluminum alloy; fatigue; corrosion; crack propagation; fracture

\section{Introduction}

2524-T3 aluminum alloy has the advantages of low density, high specific strength, excellent corrosion resistance, good formability, and low cost, so it is the main material in aircraft, vehicles, bridges, engineering equipment, and large pressure vessels [1-3]. In the service process, 2524-T3 aluminum alloy undergoes the alternating load for a long time, which has high requirements for the fatigue resistance of structural materials [4-6]. Especially in coastal areas and industrial areas with serious air pollution, structural parts are exposed to varying degrees of corrosive environments, such as salt spray and acid rain $[4,7,8]$. Under the interaction and synergy of alternating stress and corrosive environment, the fatigue resistance of components is significantly lower than that of ordinary mechanical fatigue, and the fatigue life is severely shortened. Corrosion fatigue is not a simple superposition of corrosion and fatigue damage but rather a process of synergy and promotion. Therefore, it has great destructive effects on the aluminum alloy structure [7,9].

Studies have been concentrated on the fatigue properties of aluminum alloys [10-12]. Zhang [13] conducted a fatigue test with A6005 aluminum alloy welded joints, demonstrating that the crack nucleation was a result of metallic oxides or discrete bar-like materials and that the crack propagation rates were inversely proportional to fractal dimension. C.S. Hattori et al. [14] studied the microstructure and fatigue properties of extruded aluminum alloys 7046 and 7108. The AA7046 displayed better tensile and fatigue properties than the AA7108. In addition, deep secondary cracks perpendicular to the growth direction of 
the main crack were visible on all fracture surfaces. In the medium and high cycle fatigue tests of the AA7108 and AA7046, the cracks advanced in a perpendicular direction to the elongated grains resulting from the extrusion process.

In recent years, research studies have been conducted on the corrosion fatigue performance of aluminum alloy materials, mostly in the aerospace field. Ye et al. [15] performed the plasma electrolytic oxidation (PEO) on 7A85 aluminum alloy, and the influence on fatigue behavior in air and $3.5 \% \mathrm{NaCl}$ solution was studied, demonstrating that PEO treatments significantly reduced the corrosion fatigue life of 7A85 aluminum alloy. R.K. et al. [16] studied the effects of corrosion on mechanical properties and fatigue life of 8011 aluminum alloy. Through tensile test and fatigue test, the research found that the corrosion had the severest destroy on the fatigue life of 8011 aluminum alloy structures. Zhang et al. [17] used ultrasonic nanocrystal surface modification (UNSM) to rejuvenate the fatigue performance of pre-corroded 7075-T651 aluminum alloy, finding that the fatigue life of the pre-corroded and UNSM treated specimens was twenty times higher than that of the only corroded specimens. Meanwhile, the reduction of the corroded surface layer and surface work hardening is beneficial for the fatigue performance rejuvenation of the pre-corroded alloy.

The relationship between the texture and grains with the fatigue properties of 2524 aluminum alloy were studied [1,3], demonstrating that the increasing of the intensity ratio of Cube to Brass texture is beneficial to the fatigue properties of 2524 aluminum alloy. Grain sizes among 50 and $100 \mathrm{~mm}$ exhibited high fatigue crack propagation resistances. When it comes to the effect of localized corrosion environment on fatigue properties of aluminum alloys, the studies reported recently [18-21] put their stress on the action of corrosion environment, especially the electrochemical effect on the fatigue life and properties.

In this paper, the corrosion fatigue properties of 2524-T3 aluminum alloy are investigated. The effect of $3.5 \% \mathrm{NaCl}$ solution on the transverse and longitudinal corrosion fatigue properties of the alloy is studied and compared. The crack initiation, crack propagation, and the fracture processes of corrosion fatigue of 25,24-T3 aluminum alloy are analyzed. The effects of microstructure, such as the lengths of cracks and the widths of fatigue striations are discussed. By measuring the length of the crack and observing the width of the fatigue striations at different stages, the change in the crack growth rate is explained.

\section{Materials and Experimental Methods}

The experimental material is a 2524-T3 aluminum alloy sheet with a thickness of $4 \mathrm{~mm}$, and its chemical composition is shown in Table 1. Rectangular specimens were selected. The longitudinal specimens were taken along the rolling direction, and the transverse specimens are taken perpendicular to the rolling direction. The width of the working section is $10 \mathrm{~mm}$, the radius of the uniform transition chamfer is $120 \mathrm{~mm}$, and the width of the clamping end is $30 \mathrm{~mm}$. The engineering drawing of the sample for the corrosion fatigue experiment is shown in Figure 1.

Table 1. Chemical compositions of 2524-T3 aluminum alloy ( $\%$, mass fraction).

\begin{tabular}{ccccccccc}
\hline $\mathbf{M g}$ & $\mathbf{Z n}$ & $\mathbf{C u}$ & $\mathbf{C r}$ & $\mathbf{T i}$ & $\mathbf{M n}$ & $\mathbf{S i}$ & $\mathbf{F e}$ & $\mathrm{Al}$ \\
\hline 1.25 & 0.005 & 4.66 & 0.001 & 0.03 & 0.59 & 0.025 & 0.035 & Bal. \\
\hline
\end{tabular}




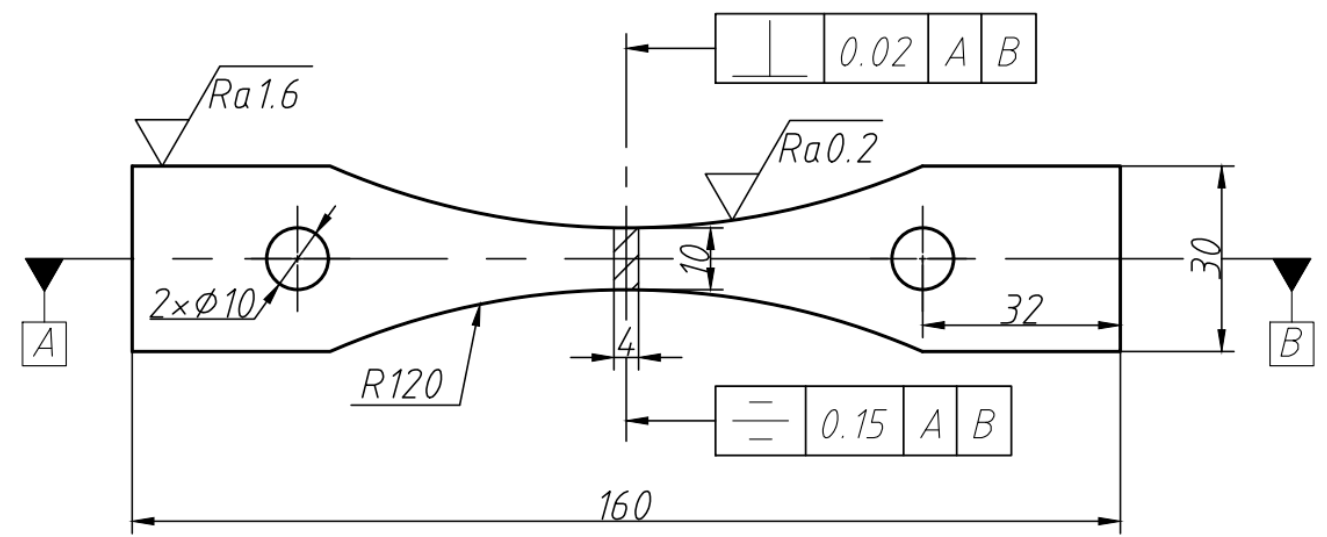

Figure 1. Engineering drawing of sample for corrosion fatigue experiment.

First, the samples were subjected to a universal tensile test on the MTS-LPS-204 universal testing machine (10 kN, MTS Industrial Co., Ltd., Eden Prairie, MN, USA) at a temperature of $25^{\circ} \mathrm{C}$. Second, the corrosion fatigue tests were conducted on the MTS858 testing machine. The standard for the corrosion fatigue test is GB/T 20120.1-2006 (Corrosion of metals and alloys Corrosion fatigue test Part 1: Cyclic failure test) of National Standardization Administration of P.R. China. Before the test, the sample was fixed in the box mounted on the fatigue testing machine, as shown in Figure 2. Then, the box was filled with $3.5 \% \mathrm{NaCl}$ solution, and the corrosion fatigue test was conducted after the box was sealed. The load was an axial sine wave, and the stress ratio $R=0$ was selected. The number of cycles is set to $10^{6}$, the test frequency is $3 \mathrm{~Hz}$, and the stress levels are 5 . The stress levels are selected according to the tensile test results, and the minimum number of samples is confirmed by the coefficient of variation.

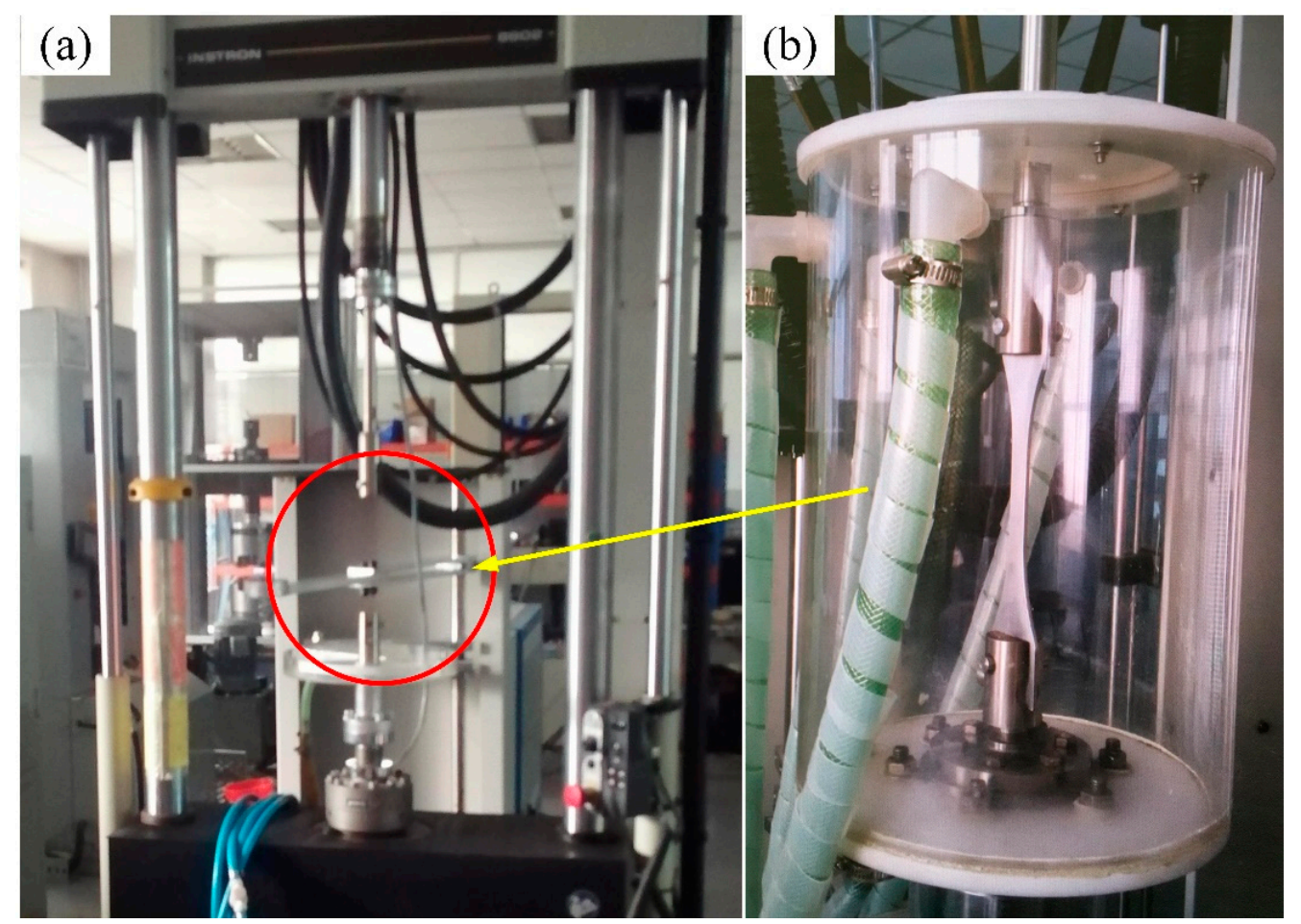

Figure 2. Setup for corrosion fatigue test: (a) MTS-LPS-204 universal testing machine; (b) box to provide corrosion experiment. 


\section{Results and Discussion}

\subsection{S-N Curves}

The universal tensile test shows that the tensile limit of 2524-T3 aluminum alloy is $475 \mathrm{MPa}$, and the first stress level of the fatigue test is selected as $190 \mathrm{MPa}$, which is $40 \%$ of the tensile limit. The stress levels of 2524-T3 aluminum alloy corrosion fatigue tests are $190 \mathrm{MPa}, 180 \mathrm{MPa}, 170 \mathrm{MPa}, 160 \mathrm{MPa}$, and $150 \mathrm{MPa}$, respectively. The effective test results of horizontal and longitudinal corrosion fatigue test of materials under different stress levels are shown in Table 2. When the stress level was $150 \mathrm{MPa}$, the fracture did not appear after loading for $10^{6}$ cycles, and the experiments finished.

Table 2. Data of horizontal and longitudinal corrosion fatigue test for 2524-T3 aluminum alloy.

\begin{tabular}{ccc}
\hline Stress Level $S_{\text {max }}$ (MPa) & $\begin{array}{c}\text { Fatigue Lifetime } \\
\text { of Horizontal Samples }\end{array}$ & $\begin{array}{c}\text { Fatigue Lifetime } \\
\text { of Longitudinal Samples }\end{array}$ \\
\hline 190 & 205,856 & 175,863 \\
190 & 235,896 & 168,566 \\
190 & 317,856 & 125,622 \\
190 & 295,586 & 192,546 \\
190 & 281,658 & 186,245 \\
180 & 302,564 & 324,556 \\
180 & 398,564 & 285,644 \\
180 & 412,563 & 385,475 \\
180 & 405,532 & 265,456 \\
180 & 546,238 & 326,384 \\
170 & 795,562 & 475,631 \\
170 & 682,536 & 568,965 \\
170 & 865,893 & 589,625 \\
170 & 795,236 & 532,563 \\
160 & 800,522 & 589,632 \\
160 & 862,456 & 632,632 \\
160 & 879,446 & 612,563 \\
160 & 952,453 & 685,136 \\
150 & 924,522 & 692,369 \\
150 & 852,365 & 663,156 \\
150 & $1,000,000$ & $1,000,000$ \\
150 & $1,000,000$ & 994,633 \\
150 & $1,000,000$ & $1,000,000$ \\
\hline & 996,223 & $1,000,000$ \\
& $1,000,000$ & $1,000,000$ \\
\hline
\end{tabular}

According to the test data in Table 2 and referring to Equations (1)-(3), the average value $\bar{x}$, standard deviation $s$, and coefficient of variation $C$ of the sub-samples to judge the validity of the data are calculated. The least-squares method [22-24] is used to obtain a safety fatigue life curve with reliability and a confidence of $50 \%$, as shown in Equations (1)-(3).

$$
\begin{gathered}
\bar{x}=\frac{1}{n} \sum_{i=1}^{n} \lg N_{i}=\hat{\mu}=\log \hat{N} \\
\sigma=\sqrt{\frac{\sum_{i=1}^{n} x_{i}^{2}-\frac{1}{n}\left(\sum_{i=1}^{n} x_{i}\right)^{2}}{n-1}} \\
C=\frac{\delta_{\max } \sqrt{n}}{p} \geq \frac{\sigma}{\bar{x}}
\end{gathered}
$$

where $\hat{\mu}$ is the population mean estimator; $\sigma$ is the population standard deviation estimator; $\delta_{\max }$ is the error limit, usually $5 \% ; p$ is the probability density, which can be determined by looking up the table for $n$. The fitted curves are shown in Figure 3. 


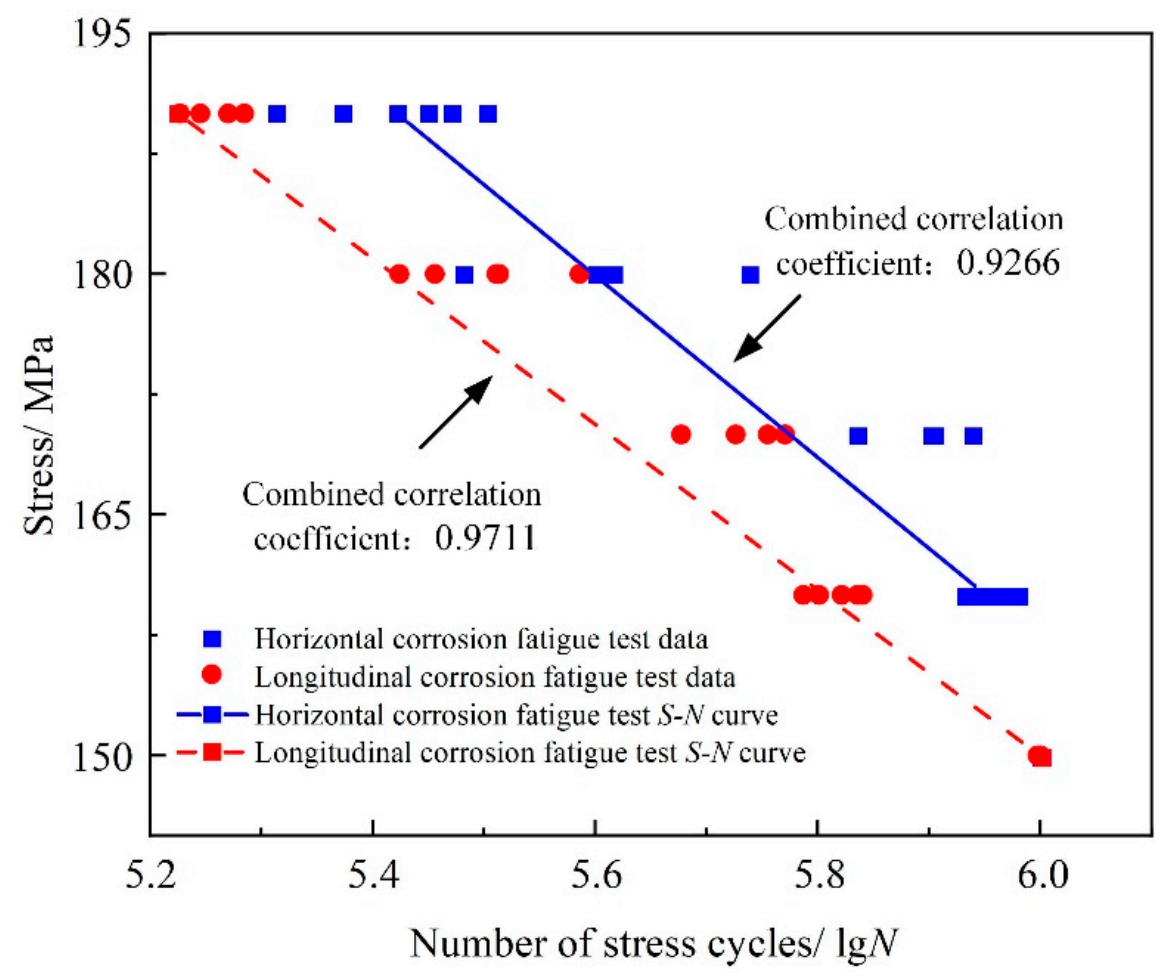

Figure 3. Horizontal and longitudinal corrosion fatigue tests for 2524-T3 aluminum alloy.

The S-N curve of the effective corrosion test under the confidence of $50 \%$ and the reliability of $50 \%$, with different horizontal and longitudinal stress levels are shown in Equations (4) and (5), respectively. The combined correlation coefficient for the curves are 0.9266 and 0.9711 , respectively.

$$
\begin{aligned}
& S=502.7457-55.2365 \lg N \\
& S=490.8512-49.5742 \lg N
\end{aligned}
$$

In Equations (4) and (5), the horizontal fatigue limit of 2524-T3 aluminum alloy corresponding to $10^{6}$ fatigue cycles is calculated to be $169 \mathrm{MPa}$, which is slightly higher than the longitudinal fatigue limit, which is $163 \mathrm{MPa}$. So, the fatigue lifetime of the longitudinal samples is slightly higher than that of the horizontal ones.

\subsection{Fracture Analysis}

Since the fracture process of the transverse and longitudinal specimens is similar, the longitudinal fracture of the specimen under $180 \mathrm{MPa}$ is taken as an example to reveal the corrosion fatigue fracture process of the aluminum alloy.

Figure 4 is the macroscopic fatigue fracture morphology of the 2524-T3 aluminum alloy. It can be roughly divided into three areas from right to left:

- $\quad \mathrm{A}$-corrosion pitting and crack-oriented zone;

- B-fatigue crack propagation zone;

- C-rapid fatigue fracture zone. 


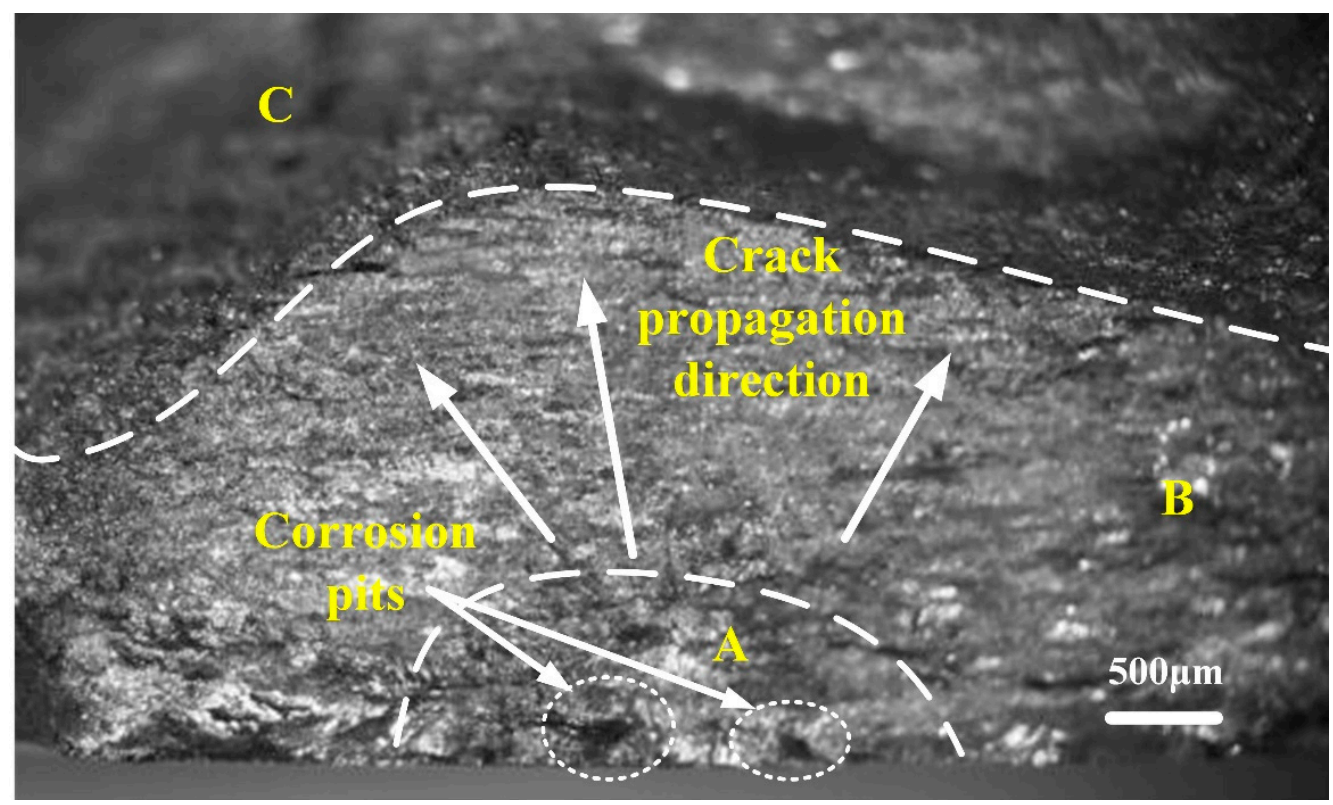

Figure 4. Morphologies of fracture specimen for 2524-T3 aluminum alloy at $180 \mathrm{MPa}$ stress level.

As observed from the macroscopic fracture, the initial crack is directly emitted from the corrosion pitting of the sample. The crack propagation rate in Zone A is very slow, and the fatigue cracks are all nucleated from the surface. The corrosion pitting morphology can be observed in part of the shell lines in the fatigue source area, revealing that the fatigue cracks are initiated by the pitting pits caused by corrosion. From Zone A to depth, the crack enters the stable propagation stage, forming a flat Zone B. The fatigue crack propagation zone is bright, indicating a brittle intergranular fracture morphology, and numerous secondary cracks can be found in this area. As the crack continues to grow, the stress intensity factor at the crack tip increases, the fatigue crack propagates sharply, and the alloy enters the rapid fracture Zone $C$, which is rough and fibrous. The boundary between Zone B and Zone C is an obvious arc-shaped crack front. Near the crack front, the fracture has the mixture characteristics of crack propagation and plastic tearing.

In the crack propagation stage, the crack front is first generated near the center of the fracture. When the crack propagates to the vicinity of the surface of the specimen, the unbroken area cannot withstand the action of external force, and it breaks along the shear direction $45^{\circ}$ to the cyclic stress. When the crack extends to Zone $C$, the plane strain fracture amount gradually decreases, and fracture occurs when it is stressed at an angle of $45^{\circ}$.

Figure 5 shows the 3D morphology of the fatigue fracture surface of the specimen in different crack regions. The dark red and dark blue in the figure indicate the highest and lowest positions, respectively.

Figure 5 a shows the surface roughness of the fatigue source region. The fatigue section is relatively rough. At this time, the crack closure is mainly affected by the roughness.

As the crack expands, it can be clearly seen that the peaks produced by the crack deflection are smoothed and flat, as shown in Figure 5b. It can be inferred that the mechanism that affects the crack closure in the medium and high stress zone has changed from roughness induction to plastic zone induction. The existence of the plastic zone at the crack tip triggers cracks in advance or mismatched contact. The original convex wave peaks are constantly squeezed during the cyclic loading process. Pressed and rubbed, it becomes flat and shiny. The plastic-induced crack closure leads to the contact between the crack surfaces in advance, and the crack-opening displacement is reduced, which indirectly reduces the driving force of crack growth, resulting in a decrease in the crack growth rate. 
(a)

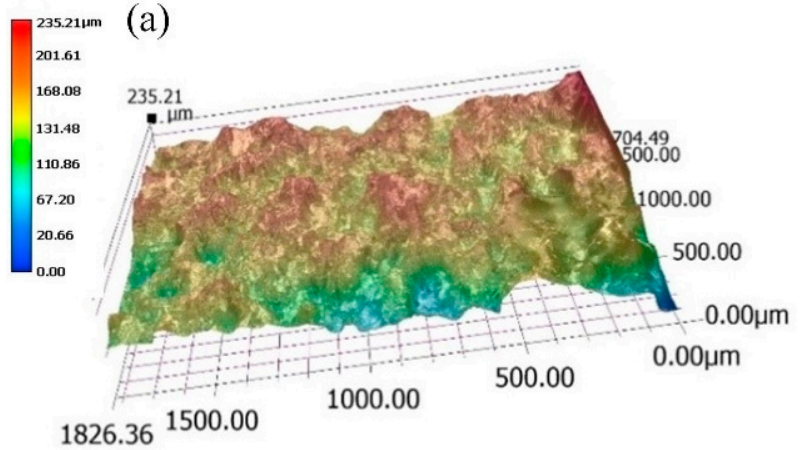

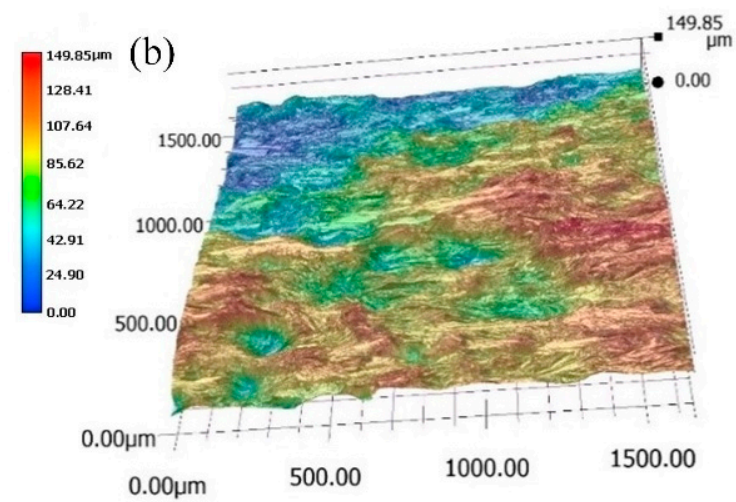

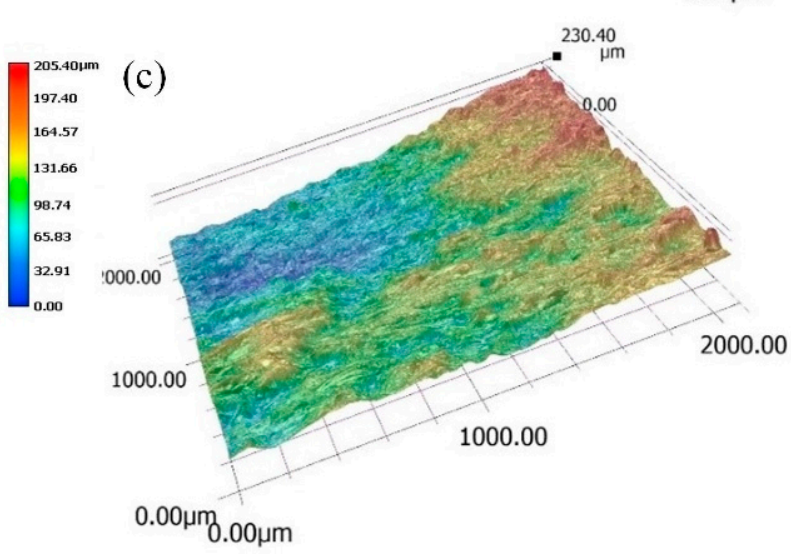

Figure 5. Three-dimensional (3D) morphology of the fatigue fracture surface of 2524-T3 aluminum alloy: (a) fatigue crack initiation zone; (b) crack propagation zone; (c) instantaneous failure zone.

In the later stage of crack propagation, the crack is in a rapid expansion state where the expansion and tearing are mixed. The crack may directly tear through several grains under each load, so the section in a small area appears very flat, as shown in Figure 5c. Meanwhile, at the upper right corner of the figure, the fracture is rising, and the feature of tearing appears.

\subsubsection{Fatigue Source and the Initial Stage of Fatigue Crack Propagation}

The SEM microscopic morphology of the fatigue source zone of the specimen after fracture at a stress level of $170 \mathrm{MPa}$ is shown in Figure 6. The crack originates from the pits generated after the surface of the material is corroded, where stress concentration occurs under the action of fatigue loads. Excessive concentrated stress causes the dislocation movement of the material surface to intensify, forming a small slip zone where fatigue cracks are generated. 


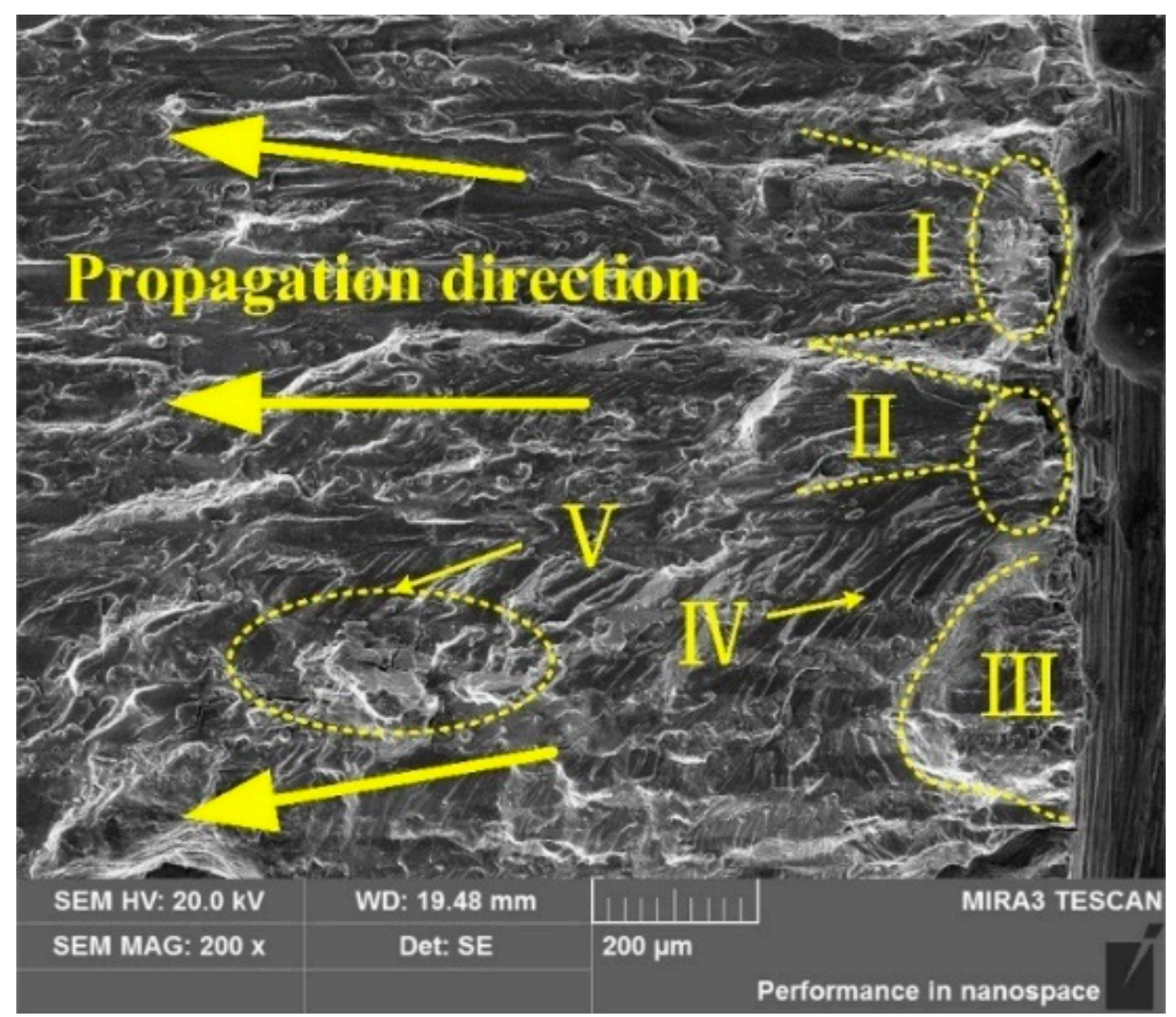

Figure 6. SEM micro-morphologies of fatigue source area.

In Figure 6, the fatigue source zone radiates toward the direction the cracks propagate and the crack front deviates in the propagation direction due to different resistances, so the crack starts to continue to expand along a series of planes with height differences, and the different fracture surfaces intersect to form steps, which constitute radial rays on the fatigue fracture. Near the corrosion pits, at Region I and Region II, the cracks originate at the corrosion pits, and there are obvious fan-shaped ray patterns along the crack propagation direction, showing ductile fracture characteristics. Region III may be affected by inclusions or twinning in the grains. The fracture characteristics feature a micro-zone cleavage mechanism under stress, and the crack source spreads around. After the main crack passes over both sides of the twinning at Region III, it continues to expand, forming a unique "tongue"-like pattern. The microscopic fracture morphology at Region IV presents the unique cleavage steps. Since the alloy has a high dislocation resistance at the grain boundary, when the crack propagates to the grain boundary, to minimize the energy consumed, the cleavage steps will expand along different crystal planes nearby. The face-centered cubic crystal structure (FCC) 2524-T3 aluminum alloy mainly slides along the direction $<1 \overline{1} 0>$ on the sliding surface $\{111\}$ [12]. As a result of the excellent toughness of 2524-T3 alloy, the proportion of the region with a brittle fracture is small. In addition, a stepped crack developed into the material at Region V, indicating that the crack tip has lateral slippage during the propagation of the main crack.

Figure 7 shows the fracture morphology of the 2524-T3 alloy at the initial stage of fatigue crack propagation. The fatigue crack propagation zone in the initial stage is flat, and the obvious quasi-cleavage fracture characteristics and wave-like pattern morphology can be seen, which is the main feature of damage in the corrosive environment. The crack propagates along a favorable direction relative to the maximum shear stress and extends to the depth of one or several grains. There are many relatively flat facets on the 
fractures with different heights. The small planes are connected by tear ridges (Figure 7a), demonstrating the crack propagations on different crystal planes. The tear ridges are deflected relative to the main crack direction, resulting in a certain angle difference in the main crack propagation direction. At the region shown by the cross-line in Figure $7 \mathrm{~b}$, the deflection angle is $32^{\circ}$. In addition, there are many micro-holes scattered on the crosssection, and the size and depth of the are different. It can be inferred that these micro-holes are caused by the coarse particles in the matrix being squeezed and stretched continuously during the crack propagation and then peeled off from the matrix.
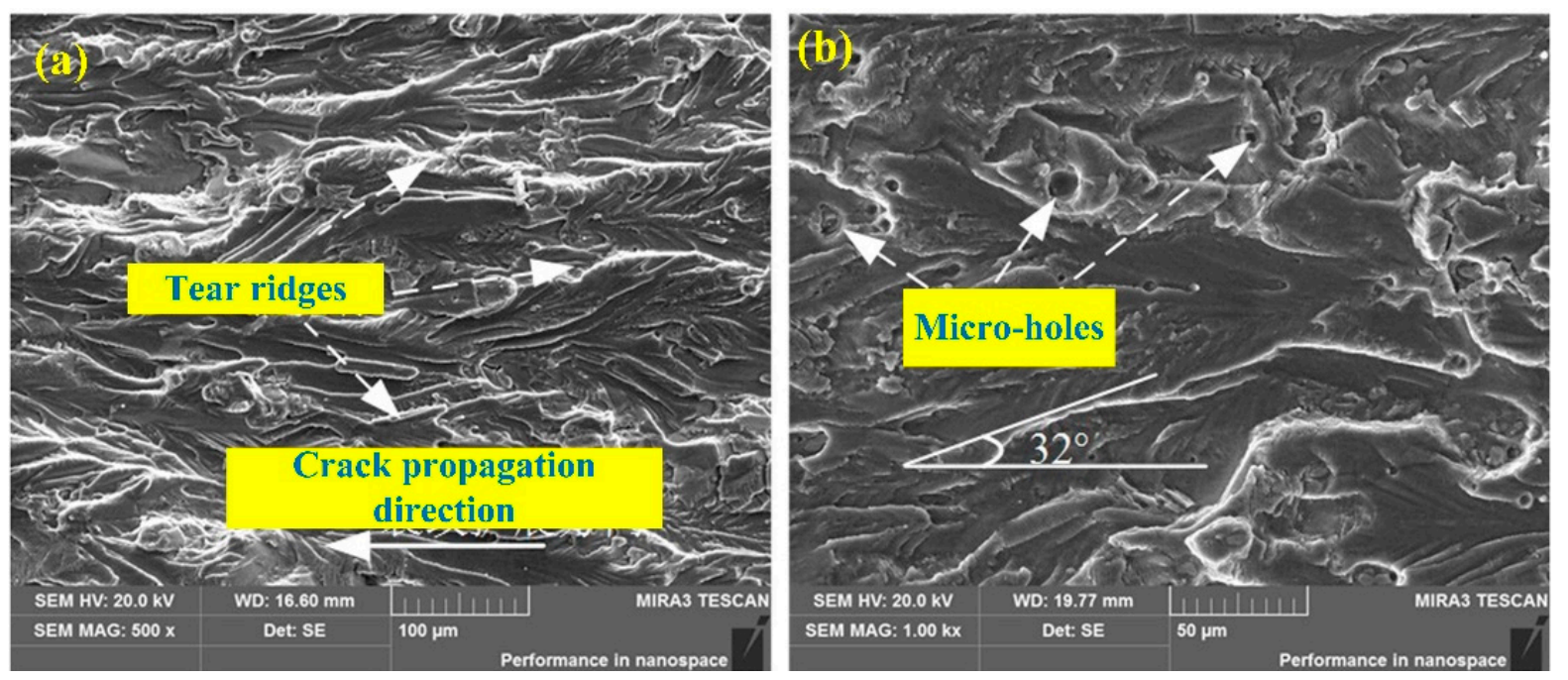

Figure 7. Morphology of fracture of 2524-T3 aluminum alloy in the initial stage of fatigue crack propagation: (a) tear ridges and crack propagation direction; (b) micro-holes and angle difference in the main crack propagation direction.

\subsubsection{Stable Stage of Fatigue Crack Propagation}

The fatigue life is mainly determined by the time of crack initiation and stable growth $[25,26]$, and the crack propagation zone is the key feature of the fatigue fracture. Figure 6 shows the stable crack propagation area at a distance of $3 \mathrm{~mm}$ and $10 \mathrm{~mm}$ from the crack initiation end. Under $\times 1000$ magnification, the main features in Figure $8 a, c$ are similar. Along the crack propagation direction, the crack propagates in the form of transgranular fracture, and there are obvious crack edges and small planes on the fracture. This is because there are differences in the local orientation of cracks when they propagate inside the alloy. The resistance and growth rates encountered at the crack front are also different. The cracks continue to deviate as they propagate along their respective favorable slip surfaces, leaving different fracture surfaces intersecting. In Figure 8, the number of steps at the crack length of $3 \mathrm{~mm}$ is larger, indicating that the crack deflection is more frequent in the initial stage of crack propagation. The fracture contains a large number of unevenly distributed micro-holes. These micro-holes are formed by the gradual separation, breaking, and peeling of the unmelted coarse second-phase particles from the matrix under the action of cyclic stress. 


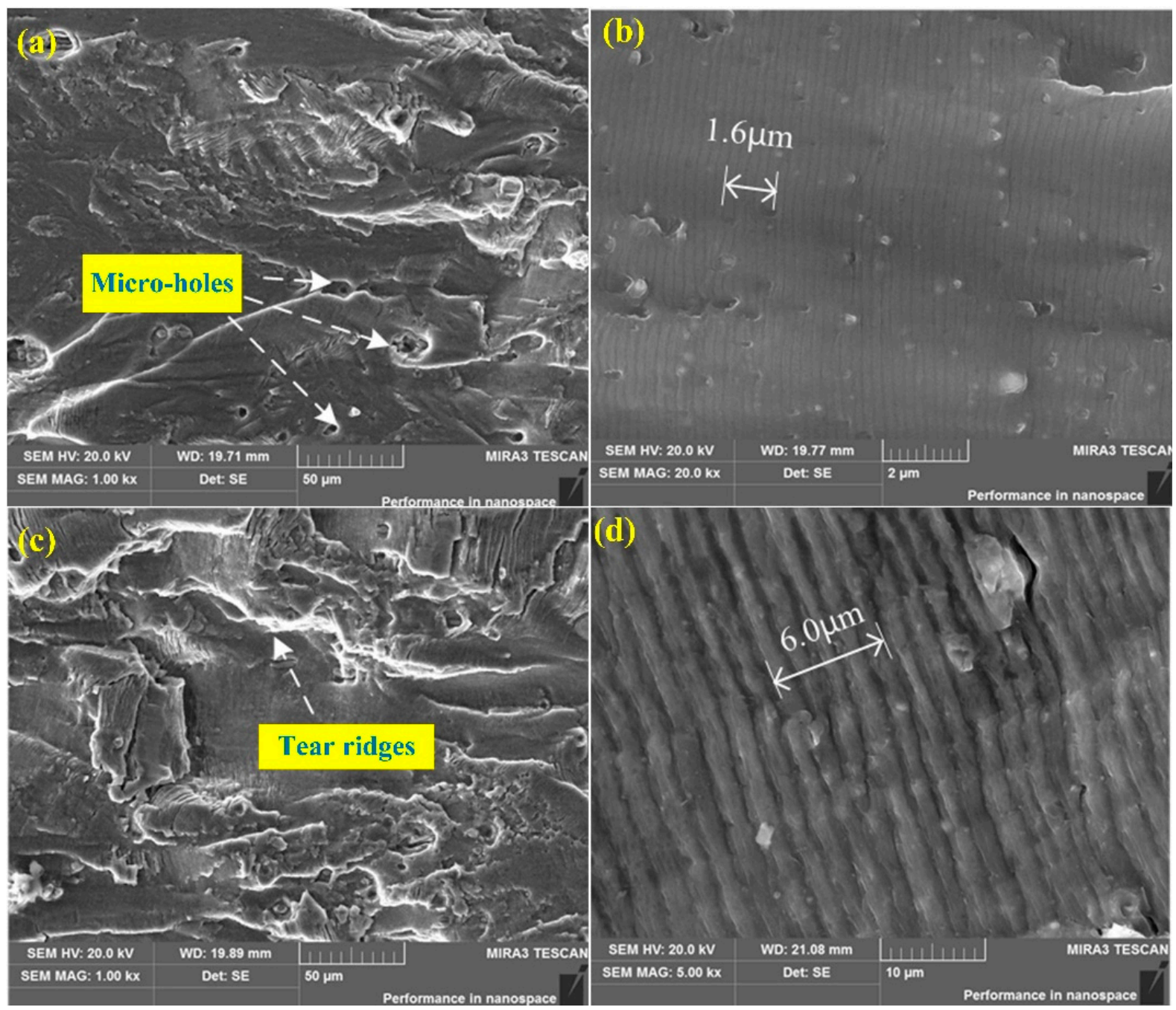

Figure 8. SEM images of stable crack propagation zone: (a,b) $3 \mathrm{~mm}$ from the crack initiation end; (c,d) $10 \mathrm{~mm}$ from the crack initiation end.

In Figure $8 b, d$, the relatively smooth areas of the fracture are further enlarged and observed, and obvious fatigue striations can be observed. Fatigue striations are the most typical microscopic feature of fatigue fracture. In Figure $8 \mathrm{~b}, \mathrm{~d}$, the thin and parallel fatigue striations are uniformly distributed, forming a group of parallel lines. The fatigue stripes on each small fracture plane are discontinuous and non-parallel, but their normal directions are along the crack propagation direction in the local fracture plane. In the process of crack propagation, the front of the crack is in an open plane strain state, and the crack propagation starts to proceed along the two slip systems at the same time or across. The double slip will cause the crack tip to be plastically passivated, i.e., fatigue striations. In Figure $8 \mathrm{~b}$, the width of the five fatigue striations is about $1.6 \mu \mathrm{m}$, and the distance of each ridge is about $0.32 \mu \mathrm{m}$, i.e., the microscopic crack propagation rate $\mathrm{d} a / \mathrm{dN}=0.32 \mu \mathrm{m} /$ cycle. The width of the five fatigue striations is significantly enlarged, about $6 \mu \mathrm{m}$, and the crack propagation rate is about three times higher than that at $3 \mathrm{~mm}$, indicating that the spacing of the fatigue striations increases with the increase in the magnitude of the stress intensity factor.

Although the formation of fatigue striations is a localized process, the general propagation trend is along the propagation direction of macroscopic cracks. As shown in Figure 9, the fatigue striations on the fracture are not all distributed in the direction of crack propagation, and some will deviate from the direction of fatigue crack propagation. As shown in Figure 9a,b, when the fatigue crack crosses from one plane to another, it will 
also leave fatigue striations on planes with different directions and uneven heights [7]. 2524-T3 aluminum alloy is solid-solution strengthened and then subjected to natural aging treatment. The intragranular is mainly a shearable coherent phase GPB zone, and its cracks will propagate along the favorable slip surface. Due to the orientation differences between the two favorable slip planes in adjacent grains, the cracks continue to grow along the favorable slip plane after growing across the grain boundary, and they gradually deflect. The fatigue striations on both sides of the grain boundary present an angle, but there is no clear change in the size of the fatigue striations on both sides. The deflection process of fatigue cracks consumes the deformation and storage energy under the action of cyclic stress, effectively reduces stress concentration, and improves the fatigue resistance of the aluminum alloy. As shown in Figure 9c, when the fatigue crack encounters the twinning boundary, it is swallowed by the twinning boundary and continues to expand $[27,28]$. The fatigue striations show a symmetrical relationship along the twin boundary, but the widths are unchanged, indicating that the co-lattice twinning interface energy in 2524 aluminum alloy is relatively low, and the effect on the crack propagation rate is not obvious. When the orientation difference of adjacent grains is not large, the crack can expand through the grain boundary and enter another grain without changing the expansion angle too much, which is conducive to the transgranular expansion of the crack and the formation of obvious straight cracks. When the crack propagates in the grain, it will preferentially propagate along a certain cleavage plane, and the propagation path may form a " $\mathrm{Z}$ "-shaped crack, as shown in Figure 9d.

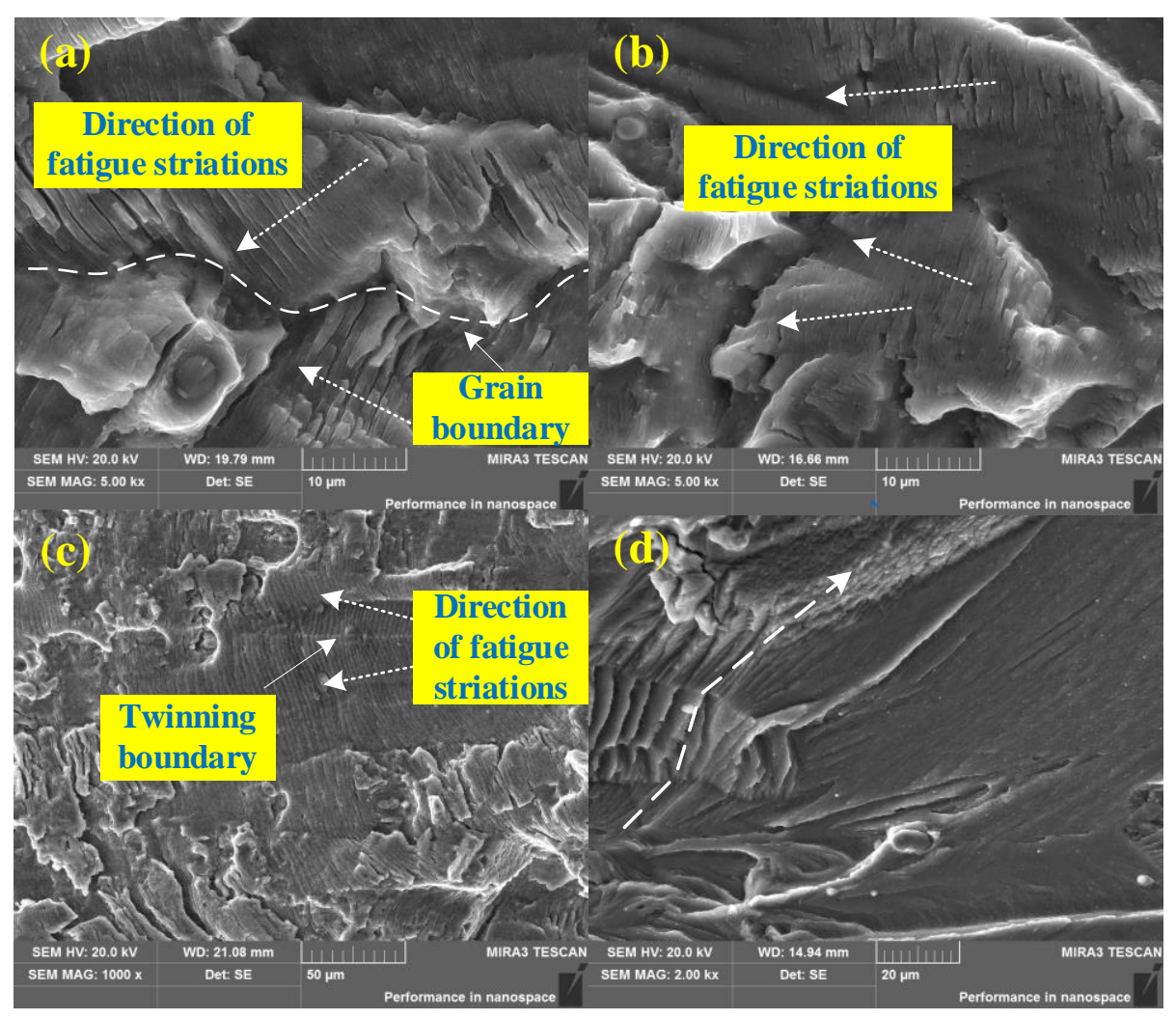

Figure 9. SEM images of different orientations in the stable crack propagation zone: $(\mathbf{a}, \mathbf{b})$ fatigue fringes on adjacent grains with different orientations; (c) twinning and fatigue fringes on both sides; (d) "Z"-shaped crack.

The 2524-T3 alloy sheet contains a large number of micron-sized second-phase particles which are generally $\mathrm{Al}_{2} \mathrm{CuMg}$ phase and Fe-rich phase. The impurity phase will leave obvious features on the fatigue fracture. As shown in Region A in Figure 10a, there are a large number of broken coarse second-phase particles and holes on the crack prop- 
agation path. This is because under the action of cyclic stress, some of the unmelted, coarse second-phase particles are torn during the crack propagation process to form broken particles, and some are separated from the matrix and leave holes. These broken particles and holes provide a preferential path for crack propagation. In Region B, because the coarse second-phase particles break under the action of cyclic stress, the fatigue striations choose to bypass the particles for expansion, indicating that the cracks tend to expand in the direction of more inclusions [29,30], bridging larger debonded inclusions, and thus, the fatigue resistance of the material is weakened.
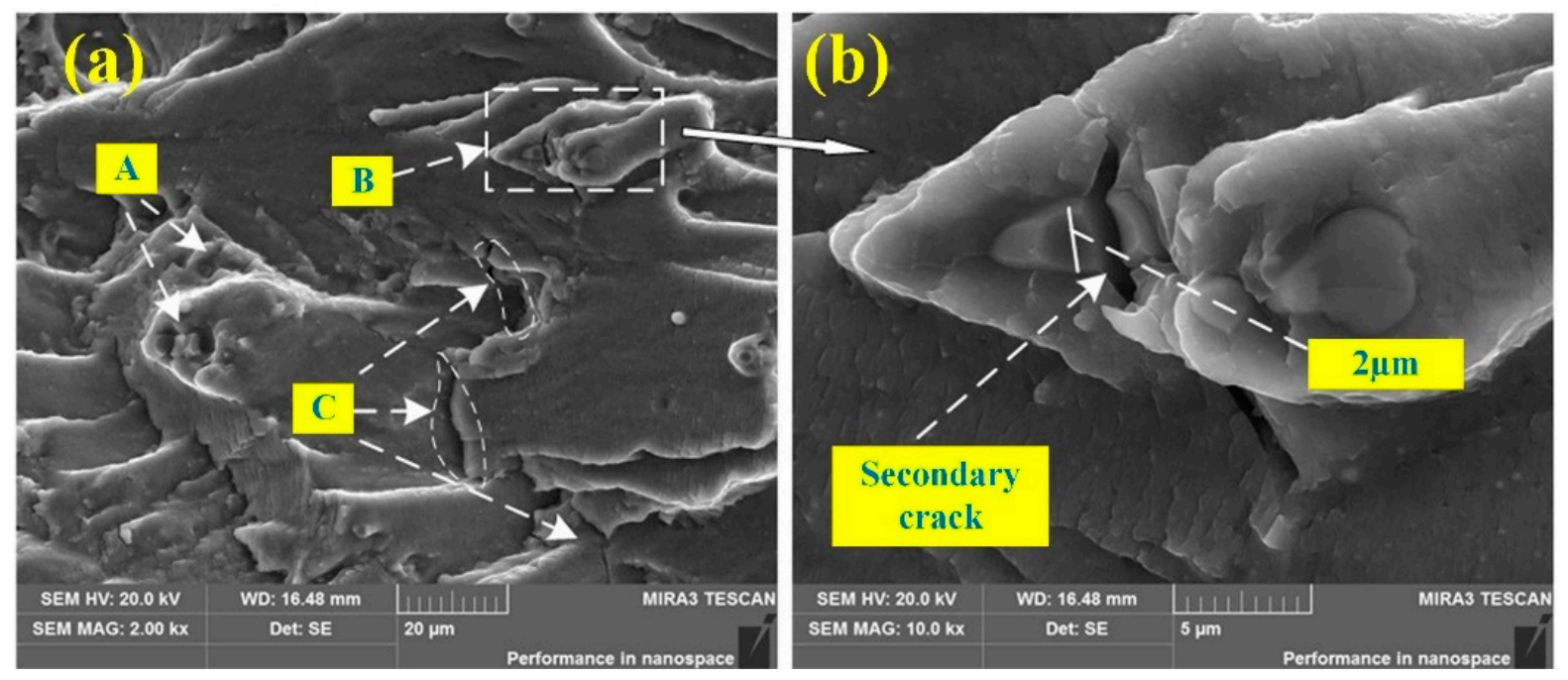

Figure 10. SEM images of coarse particles and secondary cracks in the stable crack propagation zone: (a) coarse particles; (b) secondary cracks.

In addition, another important feature of 2524 aluminum alloy during the crack propagation process-secondary cracking - was observed on the fracture. As shown in Region C in Figure 10a, there are a large number of secondary cracks distributed along the direction of the glare on the fatigue fracture. They are cracks that expand from the surface of the fracture to the inside, which is distributed intermittently on the fracture, and the directions are often parallel to the fatigue striations, but the depths are much greater than the depths of the striations. Some secondary cracks are initiated and propagated along the second-phase particles (in Figure 10b). Golden et al. [31] explained this phenomenon, demonstrating that stress concentration leads to the accumulation of dislocations that generate along the weak position of the phase interface, and the stress is relieved after the second cracking. From the point of view of the energy method, the fatigue damage process is the accumulation of strain energy in the plastic zone under cyclic stress [32,33]. The formation of secondary cracks is beneficial to release the energy at the crack tip and slow down the crack propagation rate to a certain extent.

\subsubsection{Stage of Rapid Fatigue Crack Propagation and Fatigue Fracture}

When the stress intensity factor amplitude of the crack tip is $\Delta K \approx 25 \mathrm{MPa} \cdot \mathrm{m}^{1 / 2}$, the crack enters the rapid growth zone, and the crack tip expands to the position shown by the dotted line of the crack front in Figure 3. Near the boundary, there is a mixed fracture morphology of the transition between the crack propagation zone and the transient zone. This area was observed under a high-power SEM electron microscope, and the results are shown in Figure 11. 

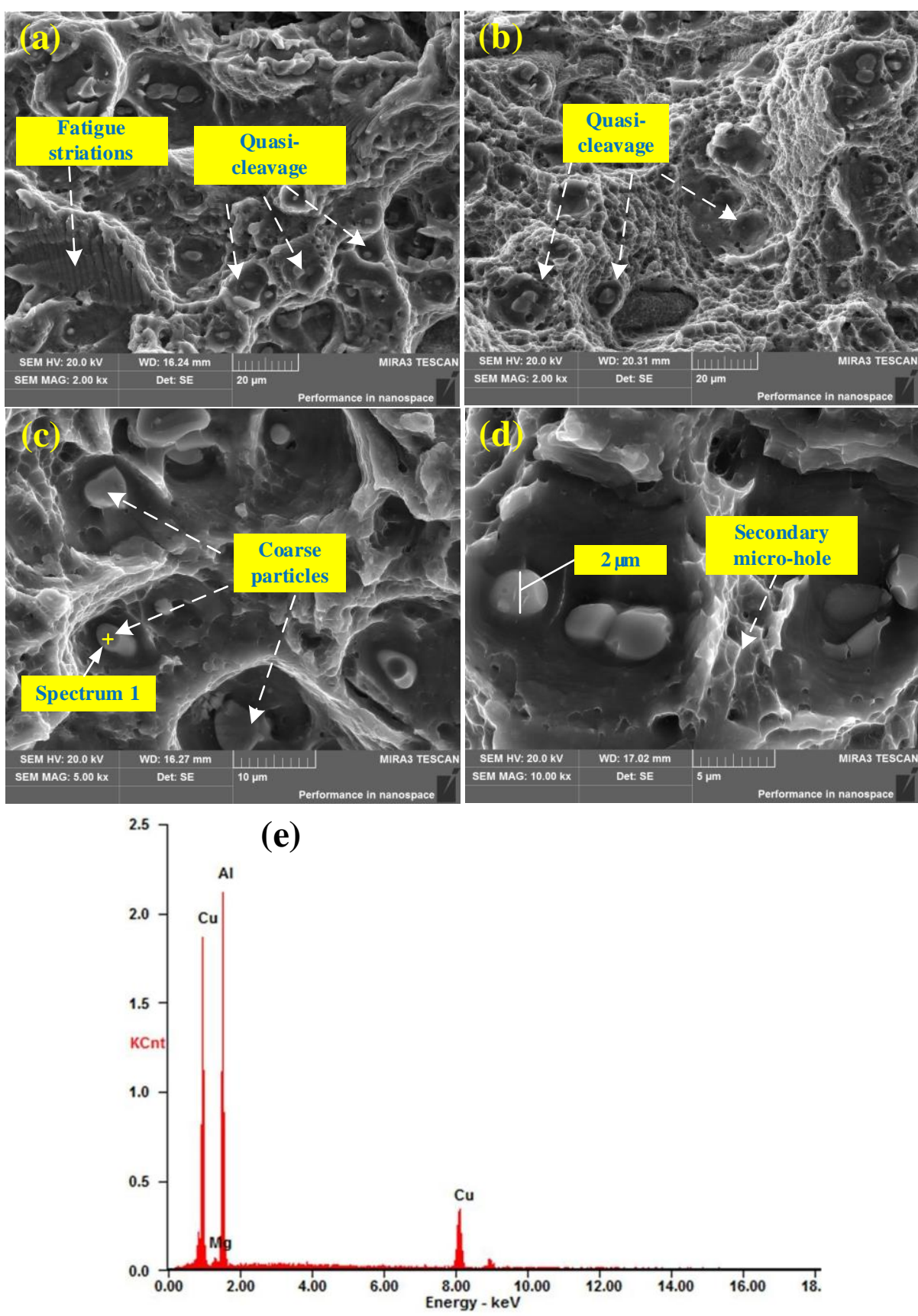

Figure 11. Microscopic morphology of the fatigue rapid growth zone: (a) crack propagation and fracture transition zone; (b) instantaneous failure zone; (c,d) enlarged views of dimples, (e) EDX map of the coarse particles.

On the right side of the dividing line (shown in Figure 11a), the crack has just transferred from the stable propagation zone to the rapid propagation zone. There are a few fatigue striations on the fracture with a large distance of $2 \mu \mathrm{m}$. The fracture morphology shows the characteristics of a mixture of fatigue bands and dimples. On the left side of the dividing line, the material begins to lose stability, and fracture occurs. The microscopic morphology begins to change from a mixed dimple-fatigue striation zone to a dimple tear zone (shown in Figure 11b). Microscopically, the fracture of the dimple is honeycomb-like, composed of many holes and small pits. The fracture morphology is characterized by quasi-static ductile tensile fracture [34], and the fracture mechanism is a microporous connection. 
Dimples are the main feature of fatigue fracture of 2524 alloy at this stage. Due to the normal tensile stress of the specimen in the test, the microscopic voids in the alloy will grow at the same rate along the three sides of the space, thus forming the equiaxed dimples in the figure. The size of the dimples is not the same. The large dimples are full of small dimples. A large number of sliding steps and tearing edges can be seen at the boundaries of the dimples. This indicates that during the rapid expansion stage, the 2524 alloy fractured after a relatively large plastic deformation. These characteristics were observed in a previous study by Magnusen et al. [10]. The process of dimple fracture is divided into three stages: microporous nucleation-growth-polymerization. In Figure 11b, it can be observed that the larger-sized dimples are all mixed with second-phase particles, with sizes ranging from 1 to $5 \mu \mathrm{m}$. The second-phase particles have an almost one-to-one relationship, which verifies the view that the second-phase particles are the source of micropore nucleation.

In the 2524 alloy, there are mainly impurity phases such as $\mathrm{Mg}_{2} \mathrm{Si}, \mathrm{Al}_{7} \mathrm{Cu}_{2} \mathrm{Fe}, \mathrm{Al}_{12} \mathrm{FeSi}$, $(\mathrm{MgFe})_{3} \mathrm{SiAl}_{12},(\mathrm{FeMn}) \mathrm{Al}_{3},(\mathrm{FeMn}) \mathrm{Al}_{6}$, and $\mathrm{S}\left(\mathrm{Al}_{2} \mathrm{CuMg}\right)$ equilibrium phase. These coarse impurity phases are very brittle, and they are easily separated from the matrix under stress or crack to form micro-holes (Figure 11c). Some strengthening phase $\left(\mathrm{Al}_{2} \mathrm{CuMg}\right)$ that are relatively firmly combined with the matrix will eventually produce micro-holes due to inconsistent plastic deformation with the matrix under the severe stress concentration in the later stage of crack propagation, as shown in Figure 11d. Excessive coarse second phases inside the alloy will severely affect the fracture toughness of the alloy. Therefore, to improve the fracture toughness of the alloy, the size and quantity of the coarse second phase should be significantly reduced. Figure 11e is an EDX map of Spectrum 1 of the coarse particle in Figure 11c. The chemical composition of Spectrum 1 is $46.9 \%$ Al, 52.5\% $\mathrm{Cu}, 0.6 \% \mathrm{Mg}$, which can be judged as $\mathrm{Al}_{2} \mathrm{Cu}$ phase, which is brittle. Under the action of alternating loads, the coarse second phase cannot simultaneously deform in coordination with the matrix, and dislocations will continue to accumulate at the particle-phase interface and cause stress concentration. When the peak stress in the local area exceeds the fracture strength of the alloy, the coarse phase will be separated from the matrix at the interface and peeled from the aluminum matrix to form cavities, which is also claimed in Ref. [35].

\section{Conclusions}

- Under the condition of $R=0,3.5 \% \mathrm{NaCl}$ corrosion solution, and the loading cycles of $10^{6}$, the horizontal and longitudinal corrosion fatigue limits of the 2524-T3 aluminum alloy are 495 and $523 \mathrm{MPa}$, respectively. The horizontal fatigue corrosion performance is slightly better than the performance of longitudinal corrosion.

- In the morphology of the fatigue fracture, the crack closure of the fatigue source region is mainly affected by the roughness. As the crack expands, the mechanism that affects the crack closure in the medium and high-stress zone has changed from roughness induction to plastic zone induction. In the later stage of crack propagation, the crack may directly tear through several grains under each load, so the section in a small area appears very flat.

- Fatigue cracks mainly originate from corrosion pits. In the initial stage of crack propagation, the fracture surface shows a mixed characteristic of ductile fracture and cleavage fracture. The cracks propagate on different crystal planes, forming small steps with different heights and deflected tear ridges.

- During the stable propagation stage of fatigue cracks, the cracks mainly propagate through the double-slip mechanism. At this stage, clear, smooth, and parallel plastic fatigue striations can be observed. The width of fatigue striations increases with the crack length or the amplitude of the stress intensity factor, and the striation direction is perpendicular to the local crack propagation direction. When the fatigue striations pass through the coarse second-phase particles, they expand by bypassing the particles, indicating that the internal cracks of the alloy tend to expand in the direction of more inclusions, bridging larger debonded inclusions, and thus, the alloy's fatigue resistance is weakened. In the rapid propagation/fracture stage, the 
crack propagation/fracture mechanism is transformed into a micro-holes connection mechanism. The main characteristic morphology at this stage is equiaxed dimples. Larger dimples are mixed with second-phase particles ranging in size from 1 to $5 \mu \mathrm{m}$. The relationship between dimples and second-phase particles is almost one-to-one, indicating that the nucleation of micropores mainly comes from the second-phase particles in the alloy.

Author Contributions: Conceptualization, C.L. and L.M.; methodology, C.L. and L.M.; validation, C.L., L.M. and Z.Z.; formal analysis, L.L. and Z.F.; investigation, C.L., L.M. and L.L.; resources, C.L.; data curation, C.L.; writing — original draft preparation, C.L.; writing—review and editing, L.M.; project administration, C.L., L.M., Z.F. and L.L. All authors have read and agreed to the published version of the manuscript.

Funding: This research was funded by the Scientific Research Fund of Hunan Provincial Education Department (grant number 20C0168 and 20B068), Changsha Municipal Natural Science Foundation (kq2007085), the Basic Scientific Research Business Project of Hebei University of Architecture (2021QNJS08), the Science and Technology Research and Development Command Plan of Zhangjiakou (1911031A), and "14th Five-Year Plan" Project of Hebei Higher Education Association (GJXH2021-109).

Data Availability Statement: The data presented in this study are available on request from the corresponding author.

Acknowledgments: The authors acknowledge Xiaohong Sun for providing support in experiments.

Conflicts of Interest: The authors declare no conflict of interest.

\section{References}

1. Shen, F.; Yi, D.; Wang, B.; Liu, H.; Jiang, Y.; Tang, C.; Jiang, B. Semi-quantitative evaluation of texture components and anisotropy of the yield strength in 2524 T3 alloy sheets. Mater. Sci. Eng. A 2016, 675, 386-395. [CrossRef]

2. Xiong, J.; Peng, X.; Shi, J.; Wang, Y.; Sun, J.; Liu, X.; Li, J. Numerical simulation of thermal cycle and void closing during friction stir spot welding of AA-2524 at different rotational speeds. Mater. Charact. 2021, 174, 110984. [CrossRef]

3. Yin, D.; Liu, H.; Chen, Y.; Yi, D.; Wang, B.; Wang, B.; Shen, F.; Fu, S.; Tang, C.; Pan, S. Effect of grain size on fatigue-crack propagation in 2524 aluminium alloy. Int. J. Fatigue 2016, 84, 9-16. [CrossRef]

4. Costenaro, H.; Lanzutt, A.; Paint, Y.; Fedrizzi, L.; Terada, M.; de Melo, H.G.; Olivier, M.-G. Corrosion resistance of $2524 \mathrm{Al}$ alloy anodized in tartaric-sulphuric acid at different voltages and protected with a TEOS-GPTMS hybrid sol-gel coating. Surf. Coat. Technol. 2017, 324, 438-450. [CrossRef]

5. Baptista, C.A.R.P.; Adib, A.M.L.; Torres, M.A.S.; Pastoukhov, V.A. Describing fatigue crack propagation and load ratio effects in Al 2524 T3 alloy with an enhanced exponential model. Mech. Mater. 2012, 51, 66-73. [CrossRef]

6. Xu, Y.; Zhan, L.; Li, W. Effect of pre-strain on creep aging behavior of 2524 aluminum alloy. J. Alloy. Compd. 2017, 691, 564-571. [CrossRef]

7. Moreto, J.; Gelamo, R.; Nascimento, J.; Taryba, M.; Fernandes, J. Improving the corrosion protection of 2524-T3-Al alloy through reactive sputtering Nb2O5 coatings. Appl. Surf. Sci. 2021, 556, 149750. [CrossRef]

8. Srivatsan, T.S.; Kolar, D.; Magnusen, P. Influence of temperature on cyclic stress response, strain resistance, and fracture behavior of aluminum alloy 2524. Mater. Sci. Eng. A 2001, 314, 118-130. [CrossRef]

9. Sonsino, C.M. Consideration of Salt-Corrosion Fatigue for Lightweight Design and Proof of Aluminium Safety Components in Vehicle Applications. Int. J. Fatigue 2021, 154, 106406. [CrossRef]

10. Magnusen, T. The cyclic fatigue and final fracture behavior of aluminum alloy 2524. Mater. Des. 2002, 23, 129-139.

11. Shen, F.; Yi, D.; Jiang, Y.; Wang, B.; Liu, H.; Tang, C.; Shou, W. Semi-quantitative evaluation of texture components and fatigue properties in 2524 T3 aluminum alloy sheets. Mater. Sci. Eng. A 2016, 657, 15-25. [CrossRef]

12. Maduro, L.P.; Baptista, C.A.R.P.; Torres, M.A.S.; Souza, R.C. Modeling the growth of LT and TL-oriented fatigue cracks in longitudinally and transversely pre-strained Al 2524-T3 alloy. Procedia Eng. 2011, 10, 1214-1219. [CrossRef]

13. Zhang, Z. Quantitative characterization on fatigue fracture features of A6005 aluminum alloy welded joints. Eng. Fail. Anal. 2021, 129, 105687. [CrossRef]

14. Hattori, C.S.; Almeida, G.F.C.; Gonçalves, R.L.P.; Santos, R.G.; Souza, R.C.; da Silva, W.C., Jr.; Cunali, J.R.C., Jr.; Couto, A.A. Microstructure and Fatigue Properties of Extruded Aluminum Alloys 7046 and 7108 for Automotive Applications. J. Mater. Res. Technol. 2021, 14, 2970-2981. [CrossRef]

15. Ye, Z.; Liu, D.; Zhang, X.; Wu, Z.; Long, F. Influence of combined shot peening and PEO treatment on corrosion fatigue behavior of 7A85 aluminum alloy. Appl. Surf. Sci. 2019, 486, 72-79. [CrossRef] 
16. Mishra, R.K. Study the effect of pre-corrosion on mechanical properties and fatigue life of aluminum alloy 8011. Mater. Today Proc. 2020, 25, 602-609. [CrossRef]

17. Zhang, R.; Zhao, W.; Zhang, H.; Yang, W.; Wang, G.-X.; Dong, Y.; Ye, C. Fatigue Performance Rejuvenation of Corroded 7075-T651 Aluminum Alloy through Ultrasonic Nanocrystal Surface Modification. Int. J. Fatigue 2021, 153, 106463. [CrossRef]

18. Moreto, J.A.; dos Santos, M.S.; Ferreira, M.O.A.; Carvalho, G.S.; Gelamo, R.V.; Aoki, I.V.; Taryba, M.; Filho, W.W.B.; Fernandes, J.C.S. Corrosion and corrosion-fatigue synergism on the base metal and nugget zone of the 2524-T3 Al alloy joined by FSW process. Corros. Sci. 2021, 182, 109253. [CrossRef]

19. Moreto, J.A.; Broday, E.E.; Rossino, L.S.; Fernandes, J.C.S.; Bose Filho, W.W. Effect of Localized Corrosion on Fatigue-Crack Growth in 2524-T3 and 2198-T851 Aluminum Alloys Used as Aircraft Materials. J. Mater. Eng. Perform. 2018, 27, 1917-1926. [CrossRef]

20. Rangel, U.; Borges, R.; Oliveira, D.A.; de Almeida, L.S.; Gelamo, R.V.; Siqueira, J.R., Jr.; Rossino, L.S.; Moreto, J.A. Corrosion and Micro-abrasive Wear Behaviour of 2524-T3 Aluminium Alloy with PAni-NPs/PSS LbL Coating. Mater. Res. 2019, 22. [CrossRef]

21. Chlistovsky, R.M.; Heffernan, P.J.; Duquesnay, D.L. Corrosion-fatigue behaviour of 7075-T651 aluminum alloy subjected to periodic overloads. Int. J. Fatigue 2007, 29, 1941-1949. [CrossRef]

22. Jiang, F.; Ding, Y.; Song, Y.; Geng, F.; Wang, Z. Digital Twin-driven framework for fatigue life prediction of steel bridges using a probabilistic multiscale model: Application to segmental orthotropic steel deck specimen. Eng. Struct. 2021, $241,112461$. [CrossRef]

23. Omrani, A.; Langlois, S.; Van Dyke, P.; Lalonde, S.; Karganroudi, S.S.; Dieng, L. Fretting fatigue life assessment of overhead conductors using a clamp/conductor numerical model and biaxial fretting fatigue tests on individual wires. Fatigue Fract. Eng. Mater. Struct. 2021, 44, 1498-1514. [CrossRef]

24. Liu, X.R.; Sun, Q. An improved macro-Micro-two-scale model to predict high-cycle fatigue life under variable amplitude loading. Contin. Mech. Thermodyn. 2021, 33, 803-816. [CrossRef]

25. Chen, Y.; Zheng, Z.; Cai, B.; Xu, J. Initiation and Propagation Behavior of Fatigue Cracks in 2197(Al-Li)-T851 Alloy. Rare Met. Mater. Eng. 2011, 40, 1926-1930.

26. Tanaka, K. The Propagation of Small Fatigue Cracks. J. Soc. Mater. Sci. Jpn. 1989, 869-887. [CrossRef]

27. Schur, E.; Afari, N.; Goldberg, J.; Buchwald, D.; Sullivan, P.F. Twin analyses of fatigue. Twin Res. Hum. Genet. 2007, 10, 729-733. [CrossRef]

28. Stein, C.A. The Role of Twin Boundaries in Fatigue Microcrack Initiation in an Advanced Nickel-Based Alloy. Ph.D. Thesis, Carnegie Mellon University, Pittsburgh, PA, USA, 2015.

29. Chen, Y.; Pan, S.; Zhou, M.; Yi, D.; Xu, D.; Xu, Y. Effects of inclusions, grain boundaries and grain orientations on the fatigue crack initiation and propagation behavior of 2524-T3 Al alloy. Mater. Sci. Eng. A 2013, 580, 150-158. [CrossRef]

30. Pippan, R.; Zelger, C.; Gach, E.; Bichler, C.; Weinhandl, H. On the mechanism of fatigue crack propagation in ductile metallic materials. Fatigue Fract. Eng. Mater. Struct. 2015, 34, 1-16. [CrossRef]

31. Golden, P.J.; Grandt, A.; Bray, G. A comparison of fatigue crack formation at holes in 2024-T3 and 2524-T3 aluminum alloy specimens. Int. J. Fatigue 1999, 21, S211-S219. [CrossRef]

32. Benam, A.S.; Yazdani, S.; Avishan, B. Effect of shot peening process on fatigue behavior of an alloyed austempered ductile iron. China Foundry 2011, 8, 325-330.

33. Azadi, M.; Shirazabad, M.M. Heat treatment effect on thermo-mechanical fatigue and low cycle fatigue behaviors of A356.0. Alum. Alloy. Mater. Des. 2013, 45, 279-285. [CrossRef]

34. Liu, Z.; Wang, J.; Gao, H.; Gao, L. Biaxial fatigue crack propagation behavior of ultrahigh molecular weight polyethylene reinforced by carbon nanofibers and hydroxyapatite. J. Biomed. Mater. Res. Part B Appl. Biomater. 2020, 108, 1603-1615. [CrossRef]

35. Chen, Y.; Tang, Z.; Pan, S.; Liu, W.; Song, Y.; Liu, Y.; Zhu, B. The fatigue crack growth behaviour of 2524-T3 aluminium alloy in an $\mathrm{Al}_{2} \mathrm{O}_{3}$ particle environment. Fatigue Fract. Eng. Mater. Struct. 2020, 43, 2376-2389. [CrossRef] 